\begin{tabular}{|c|c|c|c|c|}
\hline Share: Social Work Jurnal & VOLUME: 10 & NOMOR: 2 & HALAMAN: 227-238 & $\begin{array}{r}\text { ISSN: 2339-0042 (p) } \\
\text { ISSN: 2528-1577 (e) } \\
\text { DOI: 10.24198/share.v10i2.29441 }\end{array}$ \\
\hline
\end{tabular}

\title{
MENANAMKAN NILAI-NILAI KEARSIPAN PADA KELUARGA STUDI KASUS DI LK3 PUSAKA YOGYAKARTA
}

\author{
Sugiyanto ${ }^{1}$, Rini Dorojati², Utami Sulistiana $^{3}$, Nelly Tiurmida ${ }^{4}$ \\ 1,2,3,4Sekolah Tinggi Pembangunan Masyarakat Desa "APMD" Yogyakarta \\ probosugiyanto@gmail.com¹, rinidorjati21@gmail.com², sulistianautami@yahoo.co.id², \\ tiurmidanelly@gmail.com ${ }^{4}$
}

\begin{abstract}
The paper titled instilling archival values in the family is the result of research at the Pusaka Family Welfare Consultation Institute (LK3) in the City of Yogyakarta. The research aims to capture the positive impact of documenting individual records as family members for themselves and families in the interests of state life.

The research approach with qualitative methods through a single case study, is retrospective towards positive developments to find trends and the direction of the development of a case. The sampling technique used was purposive sampling, primary and secondary data were collected through observation, interviews and Pusataka studies. To ensure the reliability of the data, the researchers conducted four steps of reliability, namely the test of credibility, transferability, dependability and conformability.

The findings of the Heritage $L K 3$ archival value research are sufficient so that this research can contribute in criticizing, creating and developing orderly and disciplined behavior that forms the family of archivists.
\end{abstract}

Keyword: archival value, Family, LK3

\section{ABSTRAK}

Paper berjudul menanamkan nilai-nilai kearsipan pada keluarga merupakan hasil penelitian di lembaga konsultasi kesejahteraan keluarga (LK3) Pusaka di Kota Yogyakarta. Penelitian bertujuan menguangkap dampak positif pendokumentasian arsip individu sebagai anggota keluarga bagi dirinya dan keluarga dalam kepentingan hidup bernegara.

Pendekatan penelitian dengan metode kualitatif melalui study kasus tunggal, bersifat retrospective kearah perkembangan yang positif untuk menemukan kecenderungan dan arah perkembangan suatu kasus. Teknik pengambilan sampel dengan purposive sampling, data primer dan sekunder dikumpulan melalui observasi, interview dan studi pusataka. Untuk menjamin reliabilitas data maka peneliti melakukan empat langkah reliabilitas, yaitu uji credibility, transferabilitas, dependability dan conformability.

Temuan penelitian nilai kearsipan LK3 Pusaka cukup memadai sehingga penelitian ini dapat berkontribusi dalam memberi criticize, membuat dan mengembangkan perilaku tertib dan disiplin yang membentuk keluarga arsiparis.

Kata kunci: nilai kearsipan, keluarga, LK3

\section{INTRODUCTION}

Menurut Peraturan Menteri Sosial Republik Indonesia Nomor 25 Tahun 2017 tentang Lembaga Konsultasi Kesejahteraan Keluarga (LK3) sebagai salah satu bentuk organisasi social yang melaksanakan penyelenggaraan kesejahteraan social yang dibentuk oleh pemerintah, masyarakat dan perguruan tinggi. LK3 sebagai unit yang memberikan pelayanan social terpadu dan 


\begin{tabular}{|c|c|c|c|c|}
\hline Share: Social Work Jurnal & VOLUME: 10 & NOMOR: 2 & HALAMAN: 227-238 & $\begin{array}{r}\text { ISSN: 2339-0042 (p) } \\
\text { ISSN: 2528-1577 (e) } \\
\text { DOI: 10.24198/share.v10i2.29441 }\end{array}$ \\
\hline
\end{tabular}

melakukan upaya promotif, preventif, kuratif dan rehabilitative dalam penanganan masalah psikososial keluarga.

Fakta yang terjadi, permasalahan yang dibawa klien ke LK3 tidak terbatas masalah psiko social, tetapi masalah lain yang erat dengan kehidupan keluarga. Sebagai salah satu contoh kasus-kasus klien LK3 Pusaka berkait dengan dokumen-dokumen anggota keluarga dan dokumen keluarga menjadi penghalang dalam mewujudkan kesejahteraan social keluarga. Mengingat setiap individu dalam keluarga setiap saat memproduksi dokumen, dan dokumen tersebut tidak saja untuk individu yang bersangkutan tetapi melebar pada anggota keluarga yang lain.

Secara alami setiap individu memiliki dokumen abadi yang diberikan oleh Tuhan Yang Maha Esa, dan Tuhan telah memberikan dokumen abadi ketika individu masih ada dalam kandungan ibunya. Dokumen-dokumen abadi tersebut adalah deoxyribo nucleic acid (DNA), golongan darah, jenis kelamin, struktur tubuh, struktur rambut dan warna rambut, warna kulit, warna suara, sidik jari, QI, frekuensi usia, sejarah kelahiran, jenis kelamin, dan jumlah kromosom (sugiyanto, 2011: 30-32). Dalam perjalanan hidup setiap individu akan memproduksi dokumen lain non alami yang dibuat oleh orang tuanya, dan ketika tiba waktunya individu yang tumbuh dewasa akan memproduksi dokumen sendiri (individu), dan dokumen kelompok karena membentuk keluarga atau berorganisasi. Dokumen-dokumen tersebut seperti dicontohkan pada tabel 1. Semua dokumen tersebut harus diarsipkan secara baik dan benar karena dokumen-dokumen tersebut sewaktu-waktu akan dipergunakan untuk kepentingan dirinya dan kepentingan orang lain dalam kehidupan berkeluarga, bermasyarakat dan bernegara.

Menurut Sunartini (2013), pengertian arsip yang dirangkum dari kamus ensiklopedi, Undang-Undang Nomor 19 Tahun 1961, Undang-Undang Nomor 71 Tahun 1971, dan menurut Lembaga Administrasi Negara, bahwa istilah record, file, archief, naskah atau berkas atau bandle, diartikan sama dengan arsip.
Selanjutnya arsip memiliki dua makna, yaitu: 1) kumpulan surat atau warkat yang mengandung arti dan mempunyai nilai guna untuk kepentingan pribadi/perseorangan yang disimpan sebegitu rupa sehingga sewaktu-waktu dipergunakan dapat ditemukan kembali dengan mudah dan cepat., 2) arsip dimaknai sebagai tempat penyimpanan kumpulan warkat atau naskah yang disusun sistematis sehingga mudah dan cepat ditemukan kembali (retrieval) apabila sewaktu-waktu diperlukan. Dalam kontek ini dokumen individu dan keluarga merupakan bagian dari record, file, archief, naskah atau berkas atau bandle, yang mengandung nilai atau arti bagi seluruh anggota keluarga.

Dari pengertian di atas bahwa aktivitas kearsipan dimulai dan dikerjakan dari individu, mengingat bahwa individu-individu dalam keluarga yang memproduksi dokumen. Akan tetapi ada beberapa produksi dokumen atas nama keluarga. Selanjutnya semua arsip disimpan sebegitu rupa sehingga sewaktu-waktu diperlukan mudah diketemukan dengan cepat, maka semua dokumen disimpan di rumah dengan rapi. Dokumen yang disimpan di dalam rumah perlu diketahui oleh anggota keluarga dan dijamin keamanannya, walaupun beberapa dokumen dapat disimpan diluar rumah seperti di bank. Dengan demikian dari segi penyimpanan dan perawatan dokumen-dokumen mudah diketemukan kembali dalam waktu yang cepat.

Berdasarkan Undang-Undang Republik Indonesia Nomor 43 Tahun 2009, bab 1 pasal 1 ayat 3 dijelaskan mengenaai beberapa pengertian arsip dan beberapa jenis arsip sebagai berikut: 1) arsip dinamis adalah, arsip yang digunakan secara langsung dalam kegiatan pencipta arsip dan disimpan selam jangka waktu tertentu, 2) arsip vital, adalah arsip yang keberadaannya merupakan persyaratan dasar bagi kelangsungan operasional pencipta arsip, tidak dapat diperbaharui, dan tidak digantikan apabila rusak atau hilang., 3) arsip aktif, adalah arsip yang frekuensi pengunaannya tinggi atau terus-menerus. Dalam konteks ini berbagai dokumen yang dimiliki individu sebagai anggota keluarga dapat dipetakan kedalam arsif aktif, arsip dinamis dan arsip vital sebagai berikut. 


\begin{tabular}{|c|c|c|c|c|}
\hline Share: Social Work Jurnal & VOLUME: 10 & NOMOR: 2 & HALAMAN: 227-238 & $\begin{array}{r}\text { ISSN: 2339-0042 (p) } \\
\text { ISSN: 2528-1577 (e) } \\
\text { DOI: 10.24198/share.v10i2.29441 }\end{array}$ \\
\hline
\end{tabular}

Tabel 1. Jenis dokumen abadi dalam klaster arsip

\begin{tabular}{|l|l|l|}
\hline No & \multicolumn{1}{|c|}{ Jenis arsip } & \multicolumn{1}{c|}{ Jenis-Jenis Dokumen } \\
\hline 1 & Arsip Aktif & $\begin{array}{l}\text { Kartu tanda penduduk (KTP), Surat ijin mengemudi (SIM), } \\
\text { Surat tanda nomor kendaraan (STNK), Kartu anjungan tunai } \\
\text { mandiri (ATM), dll }\end{array}$ \\
\hline 2 & Arsip Dinamis & $\begin{array}{l}\text { Kartu pelajar atau kartu mahasiswa, Surat bukti kehilangan, } \\
\text { Surat keterangan catatan kepolisian (SKCK), Surat keterangan } \\
\text { hasil ujian (SKHU), dll }\end{array}$ \\
\hline 3 & Arsip Vital & $\begin{array}{l}\text { Kartu keluarga atau C1, Akte kelahiran, Akte nikah, Akte } \\
\text { kematian, Sertifikat tanah, Ijazah, Faktur pembelian, Nomor } \\
\text { pokok wajib pajak (NPWP), dll }\end{array}$ \\
\hline
\end{tabular}

Sumber: data primer diolah 2017

Kaitannya dengan tatakehidupan bernegara semua dokumen yang tertera di dalam tabel 1 diatas jika hilang atau rusak dapat dicarikan surat keterangan sebagai penganti. Pada arsip vital dokumen kartu keluarga, akte tanah dan rumah, surat nikah dan akte kematian merupakan dokumen bersifat universal yang dimiliki setiap keluarga.

Memperhatikan banyak dokumen yang diproduksi oleh individu dan keluarga maka penting bagi setiap anggota keluarga memahami nilai-nilai kearsipan. Atas dasar itu paper ini menjadi penting disajikan dihadapan public mengingat berbagai kasus yang terjadi di LK3 Pusaka. Apabila anggota keluarga membutuhkan salah satu dokumen tersebut kesulitan menemukan maka akan berdampak pada masalah yang lain. Tabel 2 sebagai contoh dari Klien LK3 Pusaka yang menghadapi masalah karena kelalian atau ketidaktertiban dalam pengarsipan dokumen individu dan dokumen keluarga.

Tabel 2 Contoh masalah keluarga yang disebabkan ketidaktertiban dokumen

\begin{tabular}{|l|l|l|}
\hline No & \multicolumn{1}{|c|}{ Sumber Masalah } & \multicolumn{1}{c|}{ Keterangan } \\
\hline 1 & $\begin{array}{l}\text { Anak usia 4 tahun } \\
\text { belum memiliki akte } \\
\text { kelahiran }\end{array}$ & $\begin{array}{l}\text { temuan lapangan beberapa anak dari klien LK3 Pusaka anak yang belum } \\
\text { memiliki akte kelahiran, ketika anak akan memasuki dunia pendidikan orang } \\
\text { tuanya kebingungan baru merasa butuh akte kelahiran. Sehingga pencarian } \\
\text { akte tidak dilakukan ketika anak lahir dengan jarak maksimal tujuh hari, } \\
\text { tetapi mencari akte kelahiran anak sudah berusia empat tahun. }\end{array}$ \\
\hline 2 & $\begin{array}{l}\text { Kesulitan membuat } \\
\text { paspor }\end{array}$ & $\begin{array}{l}\text { Klien inisial A konsultasi berkait dengan kondisi ibu kandungnya bernama W } \\
\text { berusia 78 tahun. Ketika W berniat menjalankan ibadah umroh (selama 78 } \\
\text { tahun W belum pernah haji dan umroh), begitu ada persyaratan membuat } \\
\text { paspor maka A sebagai anaknya mengalami kesulitan dan butuh waktu } \\
\text { panjang untuk membuatkan paspor untuk W. Sebab W kehilangan surat } \\
\text { nikah dan tidak pernah melapor kepada yang berwajib, tidak memiliki ijazah } \\
\text { dan tidak memiliki akte kelahiran. }\end{array}$ \\
\hline 3 & $\begin{array}{l}\text { Harga jual mobil } \\
\text { turun karena tidak } \\
\text { ada faktur }\end{array}$ & $\begin{array}{l}\text { Kasus klien bapak berinisial T, ketika T akan menjual mobil, maka T ditanya } \\
\text { calon pembeli, "pak faktur pembeliannya ada atau tidak?" T hanya dapat } \\
\text { menunjukan surat tanda nomor kendaraan (STKN ) dan BPKB, faktur lupa } \\
\text { menyimpan dan kemungkinan dibuang. Dampak hilangnya faktur nilai jual } \\
\text { mobil menjadi menurun. }\end{array}$ \\
\hline
\end{tabular}

Sumber: data sekender 2018

Tabel 2 sebagai contoh kecil dari sebagaian masyarakat yang mengabaikan dokumen, atau dokumen tidak diarsipkan dengan baik, serta menganggap dokumen sebagai hal yang tidak penting sehingga diabaikan. Kondisi ini menyebabkan persepsi negative masyarakat terhadap pelayanan pemerintah dianggap sulit dan berbelit-belit. Sebenarnya pemerintah tidak berniat mempersulit pelayanan, karena persyaratan kurang lengkap atau masyarakat belum memiliki persyaratan tertentu, sehingga menyebabkan pelayanan menjadi lama, sehingga terjadi 


\begin{tabular}{|c|c|c|c|c|}
\hline Share: Social Work Jurnal & VOLUME: 10 & NOMOR: 2 & HALAMAN: $227-238$ & $\begin{array}{r}\text { ISSN: 2339-0042 (p) } \\
\text { ISSN: 2528-1577 (e) } \\
\text { DOI: 10.24198/share.v10i2.29441 }\end{array}$ \\
\hline
\end{tabular}

patologi administrasi berdampak menambah beban biaya masyarakat.

\section{RESEARCH METHODS}

Penelitian ini mengunakan pendekatan metode kualitatif dengan study kasus tunggal Creswell (2016), bersifat retrospective kearah perkembangan yang positif, diperlukan untuk menemukan kecenderungan dan arah perkembangan suatu kasus. Teknik pengambilan sampel dengan purposive sampling, dalam penelitian ini ketua LK3 Pusaka dan seorang konsultan bidang psikologi ditetapkan sebagai sampling. Peneliti sengaja memilih sampling (informan) yang dapat memasok informasi ke peneliti selengkap mungkin dengan pemperhatikan tempat, waktu dan aktivitas sampling. Lokasi Penelitian di LK3 Pusaka berbasis Perguruan tinggi, yaitu di Sekolah Tinggi Pembangunan Masyarakat Desa "APMD" Yogyakarta.

Jenis dan sumber data : 1) data primer diperoleh dari sampling (ketua Lk3 Pusaka dan konsultan), 2) data sekunder data diperoleh dari dokumen laporan tahunan LK3 Pusaka dan buku catatan kosultasi klien. Teknik pengumpulan data dilakukan dengan teknik observasi, interview dan studi dokumentasi. Untuk menjamin reliabilitas data maka peneliti melakukan empat langkah reliabilitas, yaitu uji derajat kepercayaan (credibility), uji keteralihan (transferabilitas), uji kebergantungan (dependability) dan uji kepastian (conformability).

\section{RESULT AND DISCUSSION}

Menurut Turner (1998) teori adalah proses mengembangkan ide-ide yang membantu kita menjelaskan bagaimana dan mengapa suatu peristiwa terjadi. Creswell (2016) teori adalah seperangkat ide, konstruk atau variabel, difinisi dan proposisi yang memberikan gambaran suatu fenomena atau peristiwa secara sistematik dengan cara menentukan hubungan antar variabel. Littlejohn dan Foss (2009) teori merupakan sebuah system konsep yang abstrak dan hubungan-hubungan konsep tersebut yang membantu kita untuk memahami sebuah fenomena.

Cormick (1994) dan Creswell (2016) menyatakan dalam penelitian kualitatif teori mempunyai dua fungsi, pertama sebagai alat yang digunakan peneliti untuk mencapai tujuan penelitian melalui usaha penelitian dalam melengkapi dan menyediakan keterangan terhadap suatu fenomena kusus, sehingga memungkinkan peneliti mengetahui sesuatu secara maksimal. Kedua teori berfungsi sebagai tujuan teori yang menghasilkan petunjuk dan kisi-kisi kerja yang harus diperhatikan oleh para peneliti. Dengan demikian teori dalam penelitian kualitatif tidak dapat ditentukan sebelum apriori, karena dalam penelitian kualitatif tidak bertujuan menguji atau membuktikan kebenaran teori. Atas dasar itu teori dikembangkan atas data yang terkumpul.

1. Konsep Keluarga

Menurut Undang-undang Nomor 1 Tahun 1974 memberikan difinisi perkawinan sebagai berikut: "perkawinana adalah ikatan lahir batin antara seorang pria dengan seorang wanita sebagai suami istri dengan tujuan membentuk keluarga (rumah tangga) yang bahagia dan kekal berdasarkan ke-Tuhanan Yang Maha esa". Menurut Undang-undang Nomor 10 Tahun 1992, keluarga merupakan unit terkecil dalam masyarakat yang terdiri atas suami istri, atau suami istri dan anak, ayah dan anak atau ibu dan anaknya. Dalam paper ini penulis menegaskan bahwa yang dimaksud keluarga adalah keluarga inti (nuclear family) dalam bentuk monogamy, yaitu keluarga yang terdiri dari ayah, ibu dan anak-anak.

Dubois (1992) mempertegas konsep keluarga sebagai unit dasar dari masyarakat, dan keluarga sejahtera adalah keluarga yang mampu melaksanakan fungsi dan tanggungjawab sosialnya dalam menyediakan pemenuhan kebutuhan kepada seluruh angota keluargannya. Atas dasar konsep tersebut keluarga merupakan kumpulan orang dengan ikatan perkawinan, kelahiran, dan adopsi yang bertujuan untuk menciptakan, mempertahanan budaya dan meningkatkan perkembangan fisik, mental, emosional serta social dari setiap anggota keluarga. Konsep ini diikuti dengan penjabaran berbagai 


\begin{tabular}{|c|c|c|c|c|}
\hline Share: Social Work Jurnal & VOLUME: 10 & NOMOR: 2 & HALAMAN: 227-238 & $\begin{array}{r}\text { ISSN: 2339-0042 (p) } \\
\text { ISSN: 2528-1577 (e) } \\
\text { DOI: 10.24198/share.v10i2.29441 }\end{array}$ \\
\hline
\end{tabular}

fungsi keluarga, yaitu: a) fungsi biologis, memberikan kesempatan anggota keluarga untuk berekreasi., b) fungsi psikologis, pendewasaan kepribadian bagi anggota keluarga., c) fungsi social budaya, meneruskan nilai-nilai budaya, sosialisasi dan pembentukan normanorma dan tingkah laku pada setiap tahapaan perkembangan anak serta kehidupan keluarga., d) fungsi sosial ekonomi, mencari sumber-sumber ekonimi untuk memenuhi fungsi lainnya., e) fungsi pendidikan, menanamkan ketrampilan, tingkah laku dan pengetahuan dalam hubungan dengan fungsi-fungsi lain.

Membiasakan

mendokumentasikan dokumen yang dimiliki setiap anggota keluarga merupakan proses pendidikan yang sarat dengan ketrampilan dan pengetahuan yang tidak saja berguna untuk dirinya, tetapi akan bermanfaat secara luas bagi seluruh anggota keluarga, masyrakat dan Negara. Kedasaran individu mengarsip seluruh dokumen sebagai bukti keberhasilan keluarga dalam memberi ruang kreativitas, pendewasaan pribadi individu dan membentuk nilai budaya keluarga. Dengan demikian fungsifungsi keluarga telah terakomodir dengan baik secara bersama-sama seluruh anggota keluarga.

2. Nilai

Aksiologi merupakan studi filosofi tentang hakikat nilai-nilai, nilai sepenuhnya berhakekat subyektif dan merupakan kenyataan, namun tidak terdapat dalam ruang waktu, tetapi dapat diketahui melalui akal yang didominan unsur obyektif berdasarkan fakta. Atas dasar itu konsep nilai merupakan komplemen dan sekaligus lawan konsep fakta. Kecenderungan kita hanya mengetahui fakta, tetapi kita harus mencari nilai, agar nilai menjadi obyektif preferensi atau penilaian kepentingan, kondisi ini dibuktikan dalam sejarah filsafat yang melahirkan sejumlah nilai.
Perkembangan teori nilai dimulai sekitar tahun 1890-an, ketika perdebatan antara Alexius Meinong dengan Cristian von Ehrenfels. Alexius Meinong menegaskan bahwa sumber nilai adalah perasaan (feeling), dan perkiraan tentang kesenangan terhadap suatu obyek. Menurut Harold, dkk (1980), sumber nilai adalah hasrat atau keinginan actual atau yang memungkinkan, artinya suatu obyek memiliki nilai karena ia menarik. Penjelasan ini menegaskan bahwa nilai adalah milik obyek itu sendiri atau disebut denganobyektivisme aksiologis. Pertanyaan yang pantas dilontarkan dalam diskusi ini adalah "apakah nilai itu obyektif atau subyektif". Jawaban atas pertanyaaan itu adalah : nilai itu "obyektif" jika ia tidak tergantung pada subyek atau kesadaran yang menilai, sebaliknya nilai itu "subyektif" jika eksistensinya, maknanya, dan validitasnya tergantung pada reaksi subyek yang melakukan penilaian, tanpa mempertimbangkan apakah ini bersifat psikis ataupun fisis.

Secara prinsip setiap nilaai dapat diverifikasi untuk menentukan benar atau salah, nilai berada dalam suatu obyek, sehingga nilai pasti ada dalam realitas. Contoh nilai kebaikan, kebenaran dan keindahan ada dalam dunia nyata dan dapat ditemukan sebagai entitas, kualitas dan hubunganhubungan seperti peti, putih, dingin, dll. Pernyataan sepahaam dengan para filosof Plato, AristotelesSt. Thomas Aquinas, Maritain, Urban, Bosanquest, dan Whitehead (Kattsoff Luis, 2004). Sumber yang sama menegaskan bahwa nilai-nilai adalah obyektif sepanjang didukung oleh argument rasional dan konsisten dalam situasi terbaik. Penentuan nilai sejalan dengan pernyataan setuju atau tidak, sebab nilai memiliki realitas sebagai keadaan pikiran terhadap obyek.

Subyektivisme

aksiologi cenderung mengabsahkan teori etika yang disebut hedoisme, sebuah teori yang menyatakan kebahagian sebagai 


\begin{tabular}{|c|c|c|c|c|}
\hline Share: Social Work Jurnal & VOLUME: 10 & NOMOR: 2 & HALAMAN: 227 - 238 & $\begin{array}{r}\text { ISSN: 2339-0042 (p) } \\
\text { ISSN: 2528-1577 (e) } \\
\text { DOI: 10.24198/share.v10i2.29441 }\end{array}$ \\
\hline
\end{tabular}

kreteria nilai. Dan naturalism yang menyakini bahwa suaatu nilai dapat direduksi kedalam suatu pernyataan psikologis. Nilai tergantung dengan pengalaman manusia dan nilai tidak memiliki realitas yang independen (relativisme aksiologi). Suatu nilai dikatakan obsolut atau abadi, apabila nilai yang berlaku sepanjang masa, serta akan berlaaku bagi sisapun tanpa memperhatikan ras, maupun kelas social. Dipihak lain ada yang beranggapan bahwa semua nilai relative sesuai dengan keinginan atau harapan manusia.

Dewey (1962) menekankan bahwa nilai tidak bersifat privat (subyektif), tetapi bersifat public, miskipin tidak bersifat obyektif dalam arti tidak terlepas dari berbagai kepentingan. Teori-teori yang didasarkan pada pandangan ini mengatakan bahwa penentuan nilai adalah ekspresi emosi atau usaha untuk membujuk yang semuanya tidak factual.

Nilai dan persepsi, ciri kusus persepsi nilai adalah ketergantungan kita pada sifat hakiki nilai itu sendiri. Kalaau nilai terpisah dari eksisensi, nilai sama sekali tidak dapat dimasukan oleh akal manusiawi yang tertuju pada eksistensi. Sebab nilai itu menampakan dirinya hanya kepada perasaanemosional, akibatnya terdapat sejenis irasionalisme nilai. Lawan irasionalisme nilai adalah rasionalisme nilai yang meredusikan ciri khusus nilai pada eksistensinya saja. Diantara kedua ekstrim ini terdapat persepsi intelektual terhadap nilai. Sebab persepsi nilai intelektual selalu dikondisikan oleh emosi dan hasrat. Ada tiga konstruksi nilai berdasarkan hierarki nilai, yaitu: a) kuntruksi kaum idealis, mereka berpandangan secara pasti terhadap tingkatkan nilai, dimana nilai spiritual lebih tinggi dari pada nilai non spiritual (nilai material). b) konstruksi kaum realis, mereka menempatkan nilai rasional dan empiris pada tingkatan atas, sebab membantu manusia menemukan realitas obyektif, hokum- hukum alam dan berfikir logis. c) konstruksi kaum pragmatis, suatu aktivitas dikatakan baik seperti yang lainnya. Apabila memuaskan kebutuhan yang penting, dan memiliki nilai instrumental dan mereka sangat sensitive terhadap nilai-nilai yang menghargai masyarakat.

Berdasarkan

beberapa pandangan tentang nilai ada dua nilai hakiki yang harus diajarkan dan ditanamankan dalam keluarga berkait dengan menanamkan nilai-nilai kearsipan, yaitu nilai instrumental dan nilai utilitarian. Pembahasan nilai instrumental dan nilai utilitarian akan dijelaskan secara luas pada bagian menanamkan nilai kerasipan dibawah ini.

3. Menanamkan nilai kearsipan

Filsafat nilai merupakan studi teori umum tentang nilai yang berhubungan dengan etika dan estetika, baik nilai itu bersifat obyektif maupun subyektif, atas dasar itu tujuan nilai untuk mengetahui apakah sesuatu itu baik atau buruk, suka atau tidak sukaa, senang atau tidak senang, dll. Sehingga dengan mengetahui nilai maka tercapailah apa yang menjadi tujuan manusia. Ada dua nilai yang harus ditanamkan kepada anggota keluarga dari dini, yaitu nilai instrumental dan nilai utilitarian.

a. Nilai instrumental

Nilai instrumental merupakan nilai yang menjadi pedoman pelaksanaan dari nilai dasar. Nilai dasar belum dapat bermakna sepenuhnya apabila belum memiliki formulasi serta parameter atau ukuran yang jelas dan konkrit. Apabila nilai instrumental itu berkaitan dengan tingkah laku manusia dalam kehidupan sehari-hari, maka nilai itu akan menjadi nilai moral. Namum apabila nilai instrumental itu berkaitan dengan suatu organisasi kemasyarakatan, maka nilai instrumental itu merupakan suatu arahan, kebijakan atau strategi yang bersumber pada nilai dasar sehingga dapat juga dikatakan bahwa nilai instrumental itu merupakan suatu 


\begin{tabular}{|c|c|c|c|c|}
\hline Share: Social Work Jurnal & VOLUME: 10 & NOMOR: 2 & HALAMAN: $227-238$ & $\begin{array}{r}\text { ISSN: 2339-0042 (p) } \\
\text { ISSN: 2528-1577 (e) } \\
\text { DOI: 10.24198/share.v10i2.29441 }\end{array}$ \\
\hline
\end{tabular}

eksplisitasi dari nilai dasar. Dalam kehidupan tatakelola rumah tangga nilai-nilai instrumental dapat ditemukan dalam fungsi-fungsi keluaarga.

Nilai praksis merupakan penjabaran lebih lanjut dari nilai instrumental dalam kehidupan yang lebih nyata dengan demikian nilai praksis merupakan pelaksanaan dari nilai-nilai instrumental.

b. Nilai utilitarian

Nilai utilitarian menempatkan pada aspek manfaat, menurut teori utilitarian suatu perbuatan adalah baik, jika membawa manfaaat, faedah atau berguna, tetapi manfaat itu harus menyangkut banyak orang (masyarakat). Aliran ini memberikan suatu norma bahwa baik buruknya suatu tindakan oleh akibat perbuatan itu sendiri, sehingga tingkah laku yang baik adalah yang menghasilkan akibat-akibat baik sebanyak mungkin dibandingkan dengan akibat-akibat dari tindakannya tersebut bagi dirinya maupun orang lain dan masyarakat. Utilitarian mempunyai tanggungjawab kepada orang yang melakukan suatu tindakan, apakah tindakan tersebut baik atau buruk, kreteria untuk menentukan baik buruknya suatu perbuatan. Atas dasar itu Frondizi (2001) bercermin pada Bentham dan Mill menyatakan "the greatest happiness of the greatest number", kebahagian terbesar dari jumlah orang terbesar. Maka teori ini berkembang pada perdebatan keadilan dan hak berdampak pada kewajiban untuk menempati, walaupun disisi lain teori ini ada kekurangan atau kelemahan bahwaa hak kelompok minoritas tertentu harus dikorbankan demi kepentingan mayoritas.

Berdasarkan data sekunder dan data primer peneliti menemukan beberapa data yang diperoleh di Dinas Kependudukan dan Catatan Sipil, Kantor Urusan Agama, Rumah Sakit, Sekolah, Bank, Kantor Lurah dan ditengah kehidupan masyarakat para klien LK3 Pusaka data sebagai berikut:

a. Dinas Kependudukan dan Catatan Sipil, ada klien menghadap petugas: "bapak saya mau membuatkan akte kelahiran ibu saya, akte akan dipergunakan untuk membuat paspor, dan paspor akan dipergunakan untuk ibadah umroh". Saat ini ibu saya usia 75 tahun, suaminya sudah meninggal, dan ibu saya tidak memiliki arsip surat nikah. Jawaban petugas : "pal syarat membuat akte kelahiran harus ada surat kelahiran dari rumah sakit atau keuarhan setempat, dan harus ada surat nikah dari orang tuanya". Kalau kesulitan buat saja duplikat surat kelahiran di kelurahan dengan keterangan lahir dari seorang ibu.... Supaya tidak perlu melampirkan surat nikah orang tuanya.

b. Bank, nasabah melapor kepada petugas bank, sebelum melapor nasabah mengambil nomor antrian, ketika giliran nomor dipanggil maka nasabah berkata; " bapak saya mau minta ganti buku tabungan, karena buku tabungan saya hilang, dan saya punya catatan nomor rekening saya, serta saya sertakan surat laporan kehilangan dari kepolisian". Jawaban petugas bank: "baik bapak, sebaiknya nomor rekening ini ditutup dan diganti dengan nomor rekening baru, agar orang yang menemukan rekening bapak tersebut tidak dapat menyalahgunakan".

c. Kantor Urusan Agama (KUA), ada seorang pemuda datang ke kantor urusan agama dengan tujuan meminta duplikat surat nikah orang tuanya : " bapak orang tua saya menikah tahun 1952, saat ini surat nikah hilang dan tidak diketahui kapan hilangnya dan dimana, foto copy juga tidak punya".

Jawaban petugas KUA: "mari saya ajak ke ruang arsip, Petugas KUA mengambil sebuah buku tebal yang sudah kusut, dan diserahkan kepada seorang pemuda. Mas silahkan di cari di buku ini, jika tidak ada dibuka satu tahun sebelumnya (1951) dan satu tahun sesudahnya (1953), jika tidak ada berarti pada waktu itu orang tua saudara tidak tercatat.

Setelah dicari, tercata data atau catatan pernikahan orang tua pemuda tersebut tidak ada, maka petugas KUA menyarankan agar pemuda tersebut melapor ke kementrian agama kabupaten dan mengusulkan untuk siding isbat.

d. Rumah Sakit

Di rumah sakit swasta di Yogyakarta, 


\begin{tabular}{|c|c|c|c|c|}
\hline Share: Social Work Jurnal & VOLUME: 10 & NOMOR: 2 & HALAMAN: 227-238 & $\begin{array}{r}\text { ISSN: 2339-0042 (p) } \\
\text { ISSN: 2528-1577 (e) } \\
\text { DOI: 10.24198/share.v10i2.29441 }\end{array}$ \\
\hline
\end{tabular}

ada pengunjung datang di ruang bersalin menemui seorang bidan, dan bertanya: " maaf bu, tadi teman saya melahirkan disini, namanya Norina, sekarang ada di kamar mana ya bu?"

Bidan mencoba mencari data di look books, dan menjawab: " maaf mbak hari ini yang melahirkan ada delapan orang, tetapi tidak ada yang bernama Norina"

Pengunjung bersikap ngeyel, maaf bu saya kesini disuruh keluarganya untuk mengantar baju, tetapi ibu bilang tidak ada, dan kami nyakin ada di rumah sakit ini."

Bidan agak emosi: "mbak saya sehari piket disini, dan setiap pasien masuk dicatat, dah ayo saya ajak nengok ke delapan kamar."

Pengunjung dan bidan melihat kamar dimulai dari kamar satu ke kamar dua dan seterusnya. Giliran sampai kamar no 3 pengunjung berkata: "maaf bu lha ini yang namanya bu Norinaalamatnya dari mana?"

Bidan spontan marah: maaf mbak pasieni di KTP namanya Parsini bukan Norina, wah menganti nama membuat orang bingung dan emosi."

Pengunjung : "maaf bu, di kos panggilannya Norina."

e. Sekolah

Disekolah seorang guru (wali kelas IX) memberi pengumuman kepada muridmuridnya:"anak-anak besuk pagi diwajibkan mengumpulkan foto copy ijazah SD dan foto copy akte kelahiran masing-masing." Keesokan harinya semua murid mengumpulkan foto copy akte kelahiran dan foto copy ijazah SD. Tiga hari berikutnya guru memanggil enam anak, keenam anak tersebut ternyata ditemukan data bahwa : dua anak ada perbedaan huruf atau ejaan antara akte lahir dengan ijazah SD, dan empat anak kota tempat lahir di ijazah dengan di akte kelahiran berbeda.

Contoh lima kasus di atas, kasus satu dan dua menunjukan individu dalam keluarga memiliki dokumen buku bank, surat nikah dan akte lahir yang tidak ddidokumen dan disimpan dengan baik, sehingga dokumen tersebut dinyatakan hilang. Kasus ketiga di KUA pengarsipan dokumen belum lengkap, sehingga ketika ada masyarakat meminta duplikat belum bias melayani dengan baik, apalagi pelayanan yang cepat. kasus keempat keberanian individu mengubah dokumen atau menganti nama, tetapi tidak dilakukan secara benar dan tidak disyahkan dipihak hukum, dampaknya membingungkan pemerintah, relasi dan pihalk lainnya. Kasus kelima anak dan orang tua tidak menyadari pentingnya kebenaran dan konsistensi dokumen individu, sehingga penulisan nama yang tidak konsisten diabaikan dan berkasus.

Atas dasar itu menanamkan nilai-nilai kearsipan perlu dikampayekan kepada masyarakat, kususnya pemahaman nilai instrumental dan nilai utilitarian harus mendarah daging bagi anggota keluarga, agar jangka waktu panjang Indonesia dapat menciptakan "keluarga menuju arsiparis" kususnya kepada keluarga-keluarga ekonomi menegah ke bawah yang tingkat pendidikannya rata-rata belum sampai pada jenjanag perguruan tinggi.

\section{HASIL dan PEMBAHASAN}

Arsiparis Casanova (1928), menjelaskan arsip sebagai penambahan dokumen-dokumen yang diciptakan selama kegiatan oleh suatu lembaga atau perseorangan, dan dipelihara untuk pelaksanaan tujuan politik, hukum dan budaya oleh lembaga atau perorangan tersebut. Dalam hal ini individu sebagai anggota keluarga memproduksi beberapa dokumen yang harus diarsipkan secara baik. Baik dokumen yang diproduksi secara perseorangan maupun diproduksi secara intitusi pada keluarga dengan tujuan politik, hokum, budaya, ekonomi, eamanan dan edukasi.

Keluarga sebagai produsen arsip harus dibuktikan dengan proses pernikahan, sebelum upacara sacral "akadnikah" calon mempelai pria dan calon mempelai wanita pasti telah memenuhi persyaratan administrasi yaitu surat pengantar dari Rukun Tetangga (RT) dan Rukun warga (RW), untuk mendapatkan pengantar ini calon mempelai harus menunjukan Kartu Taanda Penduduk (KTP) dan Kartu Keluarga (KK). KTP menunjukan dokumen pribadi dan KK menunjukan dokumen keluarga. Setelah upacara akadnikah selesai kedua individu tersebut memiliki dokumen baru yaitu surat atau disebut akte nikah. Kedudukan pengantar 


\begin{tabular}{|c|c|c|c|c|}
\hline Share: Social Work Jurnal & VOLUME: 10 & NOMOR: 2 & HALAMAN: 227-238 & $\begin{array}{r}\text { ISSN: 2339-0042 (p) } \\
\text { ISSN: 2528-1577 (e) } \\
\text { DOI: 10.24198/share.v10i2.29441 }\end{array}$ \\
\hline
\end{tabular}

sebagai dokumen yang dilegalisasi di kantor Kelurahan, Kantor Kecamatan dan di bawa ke KUA untuk mendaftarkan diri dalam rencana pernikahan.

Setelah membentuk keluarga baru maka saat pertemuan awal seorang suami istri masing-masing membawa beraneka dokumen pribadi, seperti surat ijin mengemudi (SIM), anjungan tunai mandiri (ATM), ijazah, dll. Dalam perjalanannya keluarga baru ini melahirkan keturunan (anak), maka kewajiban orang tuanya mencarikan akte kelahiran. Urutan perjalanana waktu berikutnya anak masuk sekolah, dan menyelesaikan jenjang pendidikan tertentu maka anak tersebut mulai memproduksi dokumen sendiri.
Disisi lain keluarga yang sehat akan mengalami tumbuhkembang perekonomian, social dan religinya, maka banyak keluargakeluarga baru maupun keluarga lama menambah fasilitas rumah tangga dengan membeli rumah, membeli mobil, dll. Pembeliaan fasilitas baru otomatis keluarga tersebut menambah dokumen. Selain dokumen yang sudah disebutkan di atas, dinamika keluarga memiliki fase produksi dokumen yang sifatnya rutin. Kerutinan produksi dokumen ada yang bulanan, semesteran, tahunan, empat tahunan, bahkan lima tahunan. Fase jenis- jenis produksi dokumen keluarga disajikan pada tabel 3 .

Tabel 3. Jenis-Jenis Dokumen Keluarga Berdasarkan waktu Produksi

\begin{tabular}{|c|c|c|c|}
\hline No & $\begin{array}{c}\text { Waktu } \\
\text { Produksi }\end{array}$ & Nama Dokumen & $\begin{array}{c}\text { Keterangan } \\
\text { (kelompok dokumen }\end{array}$ \\
\hline \multirow[t]{3}{*}{1} & $\begin{array}{l}\text { Sekali dalam } \\
\text { hidup bersifat } \\
\text { permanen }\end{array}$ & $\begin{array}{ll}\text { a. } & \text { Kartu keluarga } \\
\text { b. } & \text { Akte kelahiran } \\
\text { c. } & \text { Akte kematian } \\
\text { d. } & \text { Ijazah TK, SD, SMP, SMA atau SMK } \\
\text { e. Surat keputusan pengangkatan pegawi negeri sipil }\end{array}$ & $\begin{array}{l}\text { Kependudukan } \\
\text { Kependudukan } \\
\text { Kependudukan } \\
\text { Pendidikan } \\
\text { Kusus warga negara } \\
\text { PNS }\end{array}$ \\
\hline & $\begin{array}{l}\text { Sekali dalam } \\
\text { hidup bersifat } \\
\text { non } \\
\text { permanen }\end{array}$ & $\begin{array}{ll}\text { f. } & \text { Akte nikah (bisa lebih dari } 1 \text { kali) } \\
\text { g. } & \text { Akte perceraian (bisa lebih dari } 1 \text { kali) } \\
\text { h. } & \text { Ijazah perguruan tinggi }\end{array}$ & $\begin{array}{l}\text { Secara umum meni - } \\
\text { kah /perceraian1 kali } \\
\text { Secara satu kali dalam } 1 \\
\text { jenjang pendidikan }\end{array}$ \\
\hline & & $\begin{array}{l}\text { a. Faktur pembelian kendaraan/mobil } \\
\text { b. Surat ijin mendirikan bangunan } \\
\text { c. Surat bukti pemasangan listrik rumah } \\
\text { d. Surat bukti pemasangan telepon rumah } \\
\text { e. Akta tanah } \\
\text { f. Surat keterangan pengalaman kerja }\end{array}$ & $\begin{array}{l}1 \text { faktur } 1 \text { pembelian } \\
1 \text { ijin } 1 \text { rumah dan } 1 \\
\text { meteran listrik-telpon. } \\
\text { Agraria }\end{array}$ \\
\hline 2 & $\begin{array}{l}\text { Per-lima } \\
\text { tahun sekali }\end{array}$ & $\begin{array}{l}\text { a. Kartu tanda penduduk (sebelum E-KTP) } \\
\text { b. Paspor }\end{array}$ & $\begin{array}{l}\text { Kependudukan } \\
\text { Imigrasi }\end{array}$ \\
\hline 3 & $\begin{array}{l}\text { Per-empat } \\
\text { tahun sekali }\end{array}$ & a. Pajak kendaraan (ganti plat nomor kendaraan) & \\
\hline 4 & Setiap tahun & $\begin{array}{l}\text { a. Bukti pembayaran pajak bumi dan bangunan } \\
\text { b. Bukti pembayaran surat tanda nomor kendaraan }\end{array}$ & \\
\hline 5 & $\begin{array}{l}\text { Per-enam } \\
\text { bulan }\end{array}$ & $\begin{array}{ll}\text { a. } & \text { Bukti pembayaran uang kuliah } \\
\text { b. } & \text { Kir kendaraan angkutan umum } \\
\text { c. } & \text { Rapor bagi siswa/murid } \\
\text { d. } & \text { Surat keterangan hasil ujian bagi mahasiswa }\end{array}$ & $\begin{array}{l}\text { Bagi mahasiswa } \\
\text { Bagi siswa TK-SMA }\end{array}$ \\
\hline 6 & Setiap bulan & $\begin{array}{ll}\text { a. } & \text { Slip gaji } \\
\text { b. } & \text { Bukti pembayaraan listrik pasca bayar } \\
\text { c. } & \text { Bukti pembayaran telepon pasca bayar } \\
\text { d. } & \text { Bukti pembayaran rekening air } \\
\text { e. } & \text { Bukti pembayaran spedi/internet } \\
\text { f. } & \text { Bukti pembayaran SPP bagi murid/siswa }\end{array}$ & $\begin{array}{l}\text { Bagi pegawai } \\
\text { PLN } \\
\text { Telekom } \\
\text { PDAM } \\
\text { Telekom } \\
\text { Pendidikan }\end{array}$ \\
\hline
\end{tabular}




\begin{tabular}{|c|c|c|c|c|}
\hline Share: Social Work Jurnal & VOLUME: 10 & NOMOR: 2 & HALAMAN: 227 - 238 & $\begin{array}{r}\text { ISSN: 2339-0042 (p) } \\
\text { ISSN: 2528-1577 (e) } \\
\text { DOI: 10.24198/share.v10i2.29441 }\end{array}$ \\
\hline
\end{tabular}

\begin{tabular}{|c|c|c|c|}
\hline & & $\begin{array}{ll}\text { g. } & \text { Belanja bulanan } \\
\text { h. } & \text { Iuran BPJS } \\
\end{array}$ & $\begin{array}{l}\text { Rumah tangga } \\
\text { Perseorangan }\end{array}$ \\
\hline 7 & $\begin{array}{l}\text { Waktu yang } \\
\text { tidak pasti }\end{array}$ & $\begin{array}{l}\text { a. Sertifikat atau piagam tanda penghargaan } \\
\text { b. Bukti transaksi di bank atau ATM } \\
\text { c. Dll }\end{array}$ & Warga berprestasi \\
\hline
\end{tabular}

Sumber: data primer diolah 2019

Tabel 3 di atas mendukung studi Rina (2012) tentang sadar arsip di lingkungan keluarga dan faktanya secara umum produk arsip atau dokumen pada tabel 3 di atas diproduksi oleh setiap keluarga, untuk itu setiap keluarga dapat mengarsipkan dokomen tersebut berdasarkan teori penyimpanan arsip. Keluarga dapat menerapkan azas kearsipan sebagai berikut: a) azas centralisasi, azas penyimpanan arsip yang dipusatkan menjadi satu dalam satu keluarga, jadi individu-individu sebagai anggota keluarga tidak perlu menyimpan sendiri-sendiri (terpusat). Contoh Kartu Keluarga (KK), Ijazah, BPKB, Akte tanah, akte kelahiran, dll disimpan menjadi satu dalam satu tempat. b) azas desentralisasi, azas penyimpanan arsip dikelola atau dipegang oleh masing-masing individu anggota keluarga, contoh KTP, SIM, ATM, Paspor, dll. Termasuk ijazah milik individu disimpan sendiri-sendiri.

Untuk penyimpanan arsip terpusat setiap anggota keluarga yang sudah remaja harus tahu atau diberitahu letaknya, jumlahnya, cara merawatnya, masa berlakunya, kegunaannya dan nomor serta kode masingmasing dokumen, misalnya nomor rekening telepon, nomor rekening listrik, nomor rekening PAM, nomor plat nomor kendaraan, nomor STNK dan BPKB masing-masing kendaraan, nomor kartu keluarga, syukur setiap anggota keluarga mengetahui nomor KTP, SIM masing-masing anggota keluarga. Sebab dokumen/arsip di atas memberi nilai kegunaan dan kehormatan untuk kepentingan anggota keluarga sebagai pencipta arsip. Dasar penilaian tidak saja memberi kegunaan dan kepentingan dalam menunjang palaksanaan kegiatan keluarga yang sedang berlangsung dan kepentingan masa yang akan datang, tetapi akan memberi nilai kegunaan dan kemudahan pada pihak lain yang berkepentingan.

Menurut John Sincair (1998), Ali dan Asrori (2010) dokumen-dokumen di atas memiliki beragaam nilai sebagai berikut: a) nilai keilmuan, bahwa bekerja berdasarkan rasionalitas, b) nilai kuasa, pertimabangan baik buruk untuk dirinya dan keluarga, c) nilai ekonomi, perbuatan individu anggota keluarga dinilai dari untung rugi secara materiil, d) nilai solideritas dan partisipasi , kepedulian terhadap anggota kelurga menjadi kuat dan berdampak bagi orang lain, e) nilai seni, rasa keindahan, keharmonisan karena saling berkomunikasi akan terwujud dalam keluarga, f) nilai agama, segala sesuatu dipandang dari sudut kepercayaan bahwa segala sesuatu itu dinilai dari kenyakinan dan kebenaran karena saling memberi trust.

Merujuk pendapat Sri Sulasmi (2014) bahwa arsip keluarga sebuah langkah kecil yang besar, artinya bahwa pengarsipan dokumen jika dilakukan oleh individu sebagai anggota keluarga dengan penuh tanggungjawab maka didalam keluarga akan terhindar dari perilaku duplikasi, pemalsuan dan penipuan untuk kepentingan-kepentingan yang melawan hukum. Oleh sebab itu semua dokumen individu dan keluarga harus dapat diidentifikasi dan dilindungi karena dokumen ini memiliki kekuatan hukum, kekuatan ekonomi, kekuatan edukasi dan privasi bagi pemiliknya.

Merujuk pendapat Scaefer and Rober, (1998) bahwa nilai dalam hal ini merupakan seperangkat prinsip etik atau moral yang fundamental dimana individu sebagai anggota keluarga harus berkomitmen, keluarga yang membiasakan mengarsip semua dokumen dengan baik secara pribadi maupun secara kelompok telah berkomitmen, maka setiap perkembangan anggota keluarga sejak anak mulai sekolah harus dikenalkan tentang dokumen alami yang bersumber dari Tuhan YME, ini adalah dokumen yang tidak bisa diubah oleh siapapun, sehingga anak diajarkan untuk bersyukur bahwa yang ada pada diri anak adalah produk Tuhan. Selanjutnya anak dikenalkan dan ditunjukan untuk belajar bertanggungjawab mana dokumen yang menjadi dokumen anak dan di produksi oleh anak, dan mana dokumen keluarga yang diproduksi keluarga, apa kegunaan masingmasing dokumen dan apa resikonya apabila 


\begin{tabular}{|c|c|c|c|c|}
\hline Share: Social Work Jurnal & VOLUME: 10 & NOMOR: 2 & HALAMAN: 227-238 & $\begin{array}{r}\text { ISSN: 2339-0042 (p) } \\
\text { ISSN: 2528-1577 (e) } \\
\text { DOI: 10.24198/share.v10i2.29441 }\end{array}$ \\
\hline
\end{tabular}

dokumen tersebut hilang atau rusak. Jadi yang harus ditanamkan pada nilai kearsipan adalah bagaimana teknik menyimpan, mengetahui fungsi, mengetahui kebenaran dokumen dan konsistensi dokumen satu dengan dokumen yang lainnya jika itu ada keterkaitan.

Berkait dengan nilai guna arsip maka semua anggota keluarga sadar bahwa semua arsip memiliki beberapa nilai atau kegunaan secara universal, jika nilai guna di atas menjadi habit anggota keleuarga dalam kehidupan sehari-hari, suatu ketika keluarga-keluarga di Indonesia akan mendapat predikat sebagai keluarga arsiparis. Keluarga arsiparis adalah sebuah nilai yang baik, nilai keluarga arsiparis adalah nilai yang mampu menjadi filosofi karena unsur religi dan budaya mampu membingkai dalam kehidupan seluruh anggota keluarga menjadi kuat atau menjadi terhormat karena saling percaya dan mempercayai (Giddens, 1995).

\section{KESIMPULAN dan SARAN}

Melalui pendekatan aksiologi bahwa perilaku manusia secara internal sarat berhubungan dengan penciptaan nilai dan secara eksternal sarat dengan penciptaan persepsi. Menurut Farid dan Hamid (2003), nilai diartikan sebagai standar atau ukuran norma yang digunakan untuk mengukur segala sesuatu yang direduksi dengan realitas dalam bungkus esensi dan psikologis. Mengacu peta teori nilai Langeveld (2007), ada dua yaitu: 1) Etika, mempersoalkan perilaku manusia dari sudu baik dan jahat dengan predikat nilai "betul" (right) dan nilai "salah" (wrong) dalam arti "susila" (moral) dan "tidak susila" (immoral). 2) Estetika, yaitu mempersoalkan penilaian atas sesuatu dari sudut indah dan jelek. Secara umum estetika disebut kajian filsafat mengenai apa yang membuat rasa senang. Sumber yang sama menyebutkan tokoh utama dibidang etika dan estetika adalah Alexander Baumgarten, bahwa nilai baik sebanding dengan nilai indah, tetapi kata "indah" sendiri lebih sering dipergunakan pada seni, sedangkan kata "baik" lebih sering dipergunakan pada perbuatan. Sedang nilai memiliki kedudukan di atas "baik". Jadi pembiasaan mengarsip dokumen individu dalam keluarga merupakan nilai baik yang perlu diajarkan sejak dini.
Temuan dalam paper ini adalah gagasan mewujudkan "keluarga arsiparis", jika individu sebagai sumber daya manusia di atas segalagalanya sumber daya yang lai di keluarga masing masing akan dan telah memiliki habit pengarsipan dokumen yang baik bagi dirinya akan berdampak positif jika individu tersebut menjadi staf atau pegawai dilingkungan instansi pemerintah atau swasta, perilaku tersebut akan terekam dalam kinerja individu. Jika individu tersebut memilih menjadi pelaku wirausaha (entrepreneur) maka perusahaannya akan tertib administrasi. Secara otomatis kantor tempat kerja dan atau perusahaan dapat memberi pelayanan yang baik, cepat dan menyenangkan kepada public.

Saran, sebaiknya unit kerja perguruan tinggi mulai mengembangkan program keluarga menuju arsiparis, karena keberhasilan keluarga arsiparis akan membantu diri sendiri anggota keluarga dan pemerintah dalam pelayanan prima diberbagai kepentingan public, dan anakanak dalam keluarga ketika memasuki usia remaja sebaiknya sudah dikenalkan dengan nomor pokok wajib pajak (NPWP), sebab NPWP merupakan bentuk pajak yang bersifat indivdu maupun institusional. Mengingat di era melineal banyak anak usia remaja sudah mulai mengembangkan hobi dengan merintis usaha. Keberhasilan anak dalam pengembangan hobi dan usaha tidak terlepas dengan peran keluarga.

Rekomendasi, penelitian ini masih perlu dilanjutkan pada LK3 berbasis masyarakat dan pemerintah serta penelitian lain yang berbasis arsiparis, mengingat tema penelitian ini selalu berkait antara individu, keluarga, pemerintah dalam berbagai aktivitas. Aktivitas yang terkai seperti pendidikan, kesehatan, transportasi, perbankan dan lain sebagainya.

\section{REFERENCES}

Brenda, Dubius and Milley. 1992. Social Work Empowering Profession, Allyn and Bocon Ine, USA.

Collin, D.J. and Colleman, H. 2007. An Introdruction to Family Social Work ( $2^{\text {nd }}$ ed). Belmont, CA: Thomson Brooks/Cole.

Cormick, T. Mc., (1995). Industry Psychology. New Dehli : Prentise Hall of India. 


\begin{tabular}{|c|c|c|c|c|}
\hline Share: Social Work Jurnal & VOLUME: 10 & NOMOR: 2 & HALAMAN: 227 - 238 & $\begin{array}{r}\text { ISSN: 2339-0042 (p) } \\
\text { ISSN: 2528-1577 (e) } \\
\text { DOI: 10.24198/share.v10i2.29441 }\end{array}$ \\
\hline
\end{tabular}

Creswell, J.W., (2016). Educational Research : Planning, counducting, and evaluating quantitative and qualitative research. Upper Saddle River. NJ: Merrill.

Dewey, J. 1962. Individualism Old and New, New York: Capricon Books.

Eugenio, C. 1928. Archivistica, Italia: Seina.

Faruk, A. 2009. Filsafat Umum, Ponorogo: STAIN PO Press

Fuad Farid, I. and Mustawalli, A.H. 2003. Cepat Menguasai IImu Filsafat. Yogyakarta: IRCisol.

Schaefer, D.W.F., (2009). Essencial of Contemporary Advertising. New York: MC. Graww Hill.

Giddens, A., (1995). Constitution of Society: The Outline the Theory of Structuration. Cambridge: Polity Press.

John Sincair. (1998). Collins Cobuilld English Language Dictianory, Glasglow.

Littlejohn, Stephen W and Karen A. Foss (2009). Teori Komunikasi, Edisis 9, Jakarta: Salemba Humanika.

Kattsoff, L.O. 2004. Element of Philosophy, Diterjemahkan oleh Soejono Soemargono, Yogyakarta: Tiarawacana.

Langenveld, M.J. 1955. Op Weg Naar Wijsgerig Denken. Diterjemahkan oleh G.J. Claessen. Jakarta: Pustaka Sarjana.

Muhammad Ali and Muhammad Asrori. 2010. Psikologi Remaja, Jakarta: PT Bumi Aksara.

Risieri Frondizi. 2001. Filsafat Nilai, Yogyakarta: Pustaka Pelajar, Uyoh Sadulloh, op cit.

Sugiyanto, (2011). Kos Krisis Center Sebagai Model Manajemen Kesejahteraan Sosial Pelajar dan Mahasiswa di Yogyakarta.
Jurnal Pembangunan Masyarakat dan Desa Volume 13. Nomor 2. Edisi Desember 2011. Sekolah Tinggi Pembangunan Masyarakat Desa "APMD" Yogyakarta.

Turner Jonathan, H., (1998). The Structure of Sociological Theory, USA: Wadsworth Publishing Company.

Rina Rakhmawati. (2012). Sadar Arsip Dilingkungan Keluarga. www.kompasiana com/rina arsipdilingkunagan keluarga diakses kamis, 5 Desember 2019, pukul 04.00.

Sri Sulasmi. (2014). Arsip Keluarga : sebuah langkah kecil yang besar. Kantor Perpustakaan dan Arsip Kabupaten Karanganyar Jawa Tengah.

Sumartini. 2013. "Rangkuman Difinis Arsif" http://bapersip.jatimprop.go.id/www.du nia arsip com.

Titus, Harold H., Marilyn Smith and Richard T, Nola. 1984. Living Issues in Phylosophy, diterjemahkan oleh H.M Rasjid, Jakarta: Bulan Bintang.

Wiramihardja and Sutardjo. A. 2007. Pengantar Filsafat, cetakan ke 2. Bandung: Refika Aditama.

Peraturan Menteri Sosial Republik Indonesia Nomor 25 Tahun 2017 tentang Lembaga Konsultasi Kesejahteraan Keluarga.

Undang-Undang Republik Indonesia Nomor 1 Tahun 1974, Tentang Perkawinan.

Undang-Undang Republik Indonesia Nomor 7 Tahun 1971, Tentang Pokok-Pokok Kearsipan.

Undang-Undang Republik Indonesia Nomor 43 Tahun 2009, Tentang Arsip 